\title{
Effects of Fatty Acids Composition on Fuel Properties of Jatropha Curcas Biodiesel
}

\author{
Edwin Khethiwe*, Ketlogetswe Clever, Gandure Jerekias \\ University of Botswana, Department of Mechanical Engineering, Gaborone, Botswana \\ Email: *edwinkhethiwe2013@gmail.com
}

How to cite this paper: Khethiwe, E., Clever, K. and Jerekias, G. (2020) Effects of Fatty Acids Composition on Fuel Properties of Jatropha Curcas Biodiesel. Smart Grid and Renewable Energy, 11, 165-180. https://doi.org/10.4236/sgre.2020.1110010

Received: May 22, 2020

Accepted: October 27, 2020

Published: October 30, 2020

Copyright (c) 2020 by author(s) and Scientific Research Publishing Inc. This work is licensed under the Creative Commons Attribution International License (CC BY 4.0).

http://creativecommons.org/licenses/by/4.0/

(c) (i) Open Access

\begin{abstract}
In the efforts to reduce effects of climate change, biodiesel fuels from plant oils such as Jatropha curcas have been proposed as alternative fuels which can be used in the transportation sector in diesel engines. The current study investigates the effects of fatty acids composition on fuel properties of biodiesel derived from Jatropha curcas seeds obtained from selected regions of Botswana. The physicochemical fuel properties investigated include kinematic viscosity, flash point, energy content, density, pour point and cloud point from derived Jatropha curcas biodiesel. Results of the study showed that Jatropha curcas biodiesel samples for all regions under review are dominated by unsaturated fatty acids which are desirable for cold flow properties and kinematic viscosity of the biodiesel fuel. The major fatty acids in Jatropha curcas biodiesel fuels from all the regions range from $69.00 \%$ to $77.81 \%$ of unsaturated fatty acids. The overall results conclude that fatty acids composition has influence on the fuel properties of the biodiesel under investigated.
\end{abstract}

\section{Keywords}

Jatropha Curcas, Fatty Acids, Fuel Quality, Engine Performance

\section{Introduction}

The ever increasing demand for energy worldwide, driven by industrialization, has led to reliance on fossil fuels to satisfy these energy needs. However, use of fossil fuels is challenged by the depletion of known resources and the negative impact of the fuel's combustion emissions on the environment which causes adverse effects such as climate change [1]. Consequently, biodiesel fuel has been identified as one of the clean alternative energy sources which can be utilized to mitigate said effects.

Due to global concerns on utilization of edible feedstock such as sunflower 
being used for fuel production, lot of work has been carried out to explore the utilisation of non-edible oils such as Jatropha curcas, mahua, neem and castor for biodiesel production [2] [3] [4]. Rutz and Rainer [5] echoed that the choice for a certain feedstock is pre-determined by factors such as agricultural, geographical and climatic conditions where the feedstock is harvested.

Since biodiesel is made of esters of fatty acids, it is therefore important to perform the esters profiles of biodiesel prior to its use. In most vegetable oil biodiesel feedstock, the major fatty acids present are: oleic, linoleic, palmitic and stearic with oleic being the dominant [6] [7] [8]. Oleic and linoleic acid form part of the unsaturated fatty acid of the biodiesel sample, that is, fatty acids with one or more double bond within their moleculer structure. Oleic acid has a single double bond in their structure while linoleic acid has two double bonds.

The unsaturated fatty acids can further be divided into two types namely: monounsaturated and polyunsaturated. The monounsaturated (Cn:1) fatty acid contains only one double bond in their chemical structure while polyunsaturated $(\mathrm{Cn}: 2,3)$ fatty acid has two or three double bonds. It is ideal for the vegetable oil used for production of biodiesel to have relatively larger percentage of monounsaturated fatty acids than polyunsaturated fatty acids. This is because oil containing relatively high proportion of polyunsaturated fatty acids tends to exhibit a poor oxidation stability and it can compromise the fuel properties such as kinematic viscosity and impair fuel quality [9] [10] [11]. Other fuel properties which are negatively affected by high degree of unsaturation are density and cetane number [6]. The authors further echoed that an increase in degree of unsaturation leads to an increase in density and decrease in cetane number of the biodiesel fuel. Oxidation stability is a measure of change in fuel quality during extended storage. Kinast [12] describes oxidation stability as an indicator of shelf life of the fuel.

On contrary, an increase in degree of unsaturation particularly monounsaturated fatty acids improves other fuel properties such as cold flow properties and kinematic viscosity [7] [8]. The authors further highlighted that higher degree of unsaturation lead to outstandingly improved low temperature performance. As for kinematic viscosity, the same authors alluded that with increase in unsaturation the kinematic viscosity reduces.

Saturated fatty acids such as palmitic and stearic do not have double bond in their molecular structure. Contrary to the discussions made earlier on poor oxidation stability of fuel with high content of polyunsaturated fatty acids (linoleic), for a good oxidation stability, the fuel should have more of saturated fatty acid [8] [13]. The discussions has demonstrated that fatty acids composition is an integral part in the biodiesel production as it has great influence in the physicochemical fuel properties of the biodiesel fuel.

Several studies have been carried out on the subject of biodiesel, and in Botswana, government conducted a feasibility study on the production and use of biofuels in 2007 [14]. According to the report, Jatropha curcas was identified as 
the most promising crop for biodiesel production in Botswana. Consequently, in 2012 the government further undertook a five (5) year research project aimed to determine appropriate method for Jatropha curcas cultivation in Botswana's climatic condition. Though much literature exists in the area of the current work, the current study is stimulated by government's ambition and efforts to develop a biodiesel sector in the country. Scientific evidence to validate biodiesel from locally grown jatropha kernel oil as good fuel was deemed necessary to inform policy. Hence the current study focuses on investigating the effect of fatty acid composition on fuel properties of Jatropha curcas biodiesel. It is the view of the authors that the results will fully support the government's efforts to stimulate rapid development of biodiesel industry in Botswana.

\section{Materials and Methods}

\subsection{Seed Preparation}

Jatropha curcas seeds were collected from selected regions of Botswana namely Paje, Serowe, Mmadinare and Tsamaya. Figure 1 shows the picture of Jatropha curcas seeds and seed kernel. All the regions are situated along the eastern side of the country. Selection of these regions was based on the availability of seeds at the time of the study. Prior to the experimental procedures, seeds were cleaned by removing foreign materials such as husk, small stones and leaves. Stones can cause deformation of the press tools and foreign material of plant origin such as weeds and stems can reduce oil quality. This step was done by hand since it was not complex. To further remove any small foreign materials, a metal sieve separator of $5 \mathrm{~mm}$ diameter was used. This is similar to a study by [15]. The seeds were then sun dried for about 3 weeks to remove moisture as in the method by [16]. It is important that the seeds are well dried before pressing since moist seeds can develop mould which can jam the pressing equipment.

\subsection{Mechanical Extraction}

Oil extraction was carried out using Kern Kraft screw press machine (KK40F Universal). After the seeds were cleaned, they were fed on the seed hopper. The rotational speed of the machine was then set at higher speeds of 80 revolutions
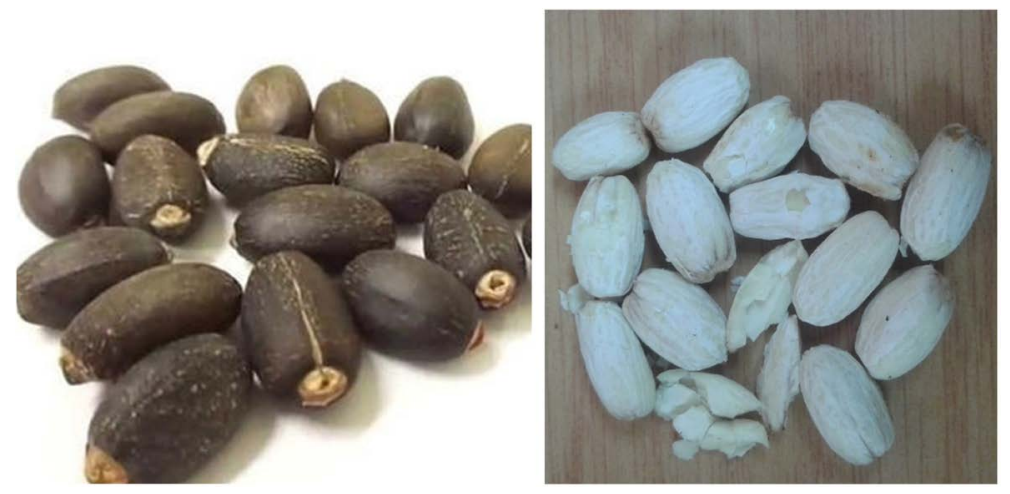

Figure 1. Jatropha curcas seeds and seed kernel. 
per minute (rpm) since Jatropha curcas seeds are hard-shelled. During the operation, oil was drained from the holes of the sieve and the press cake continuously ran from the pre-jet.

\subsection{Biodiesel Production}

Jatropha curcas crude oil was processed into biodiesel. In order to achieve this, the alkali catalysed transesterification process was used. This process was performed using Biodiesel Starter Kit sourced from Division of Reliance Energy Resources, LLC in Florida, United States of America. The laboratory scale biodiesel processing unit works in four stages namely; heating of oil, transesterification process, separation and dry washing as demonstrated in Figure 2.

\subsection{Oil Characterization}

Oil characterization involves the chemical composition of different derived biodiesel samples to establish its fatty acid profiles. The test method involved analysis of the standard as a reference sample as described in Section 2.4.1 to establish the major esters. Thereafter the biodiesel samples were analysed following the

\section{STAGE 2 -TRANSESTERIFICATION PROCESS}

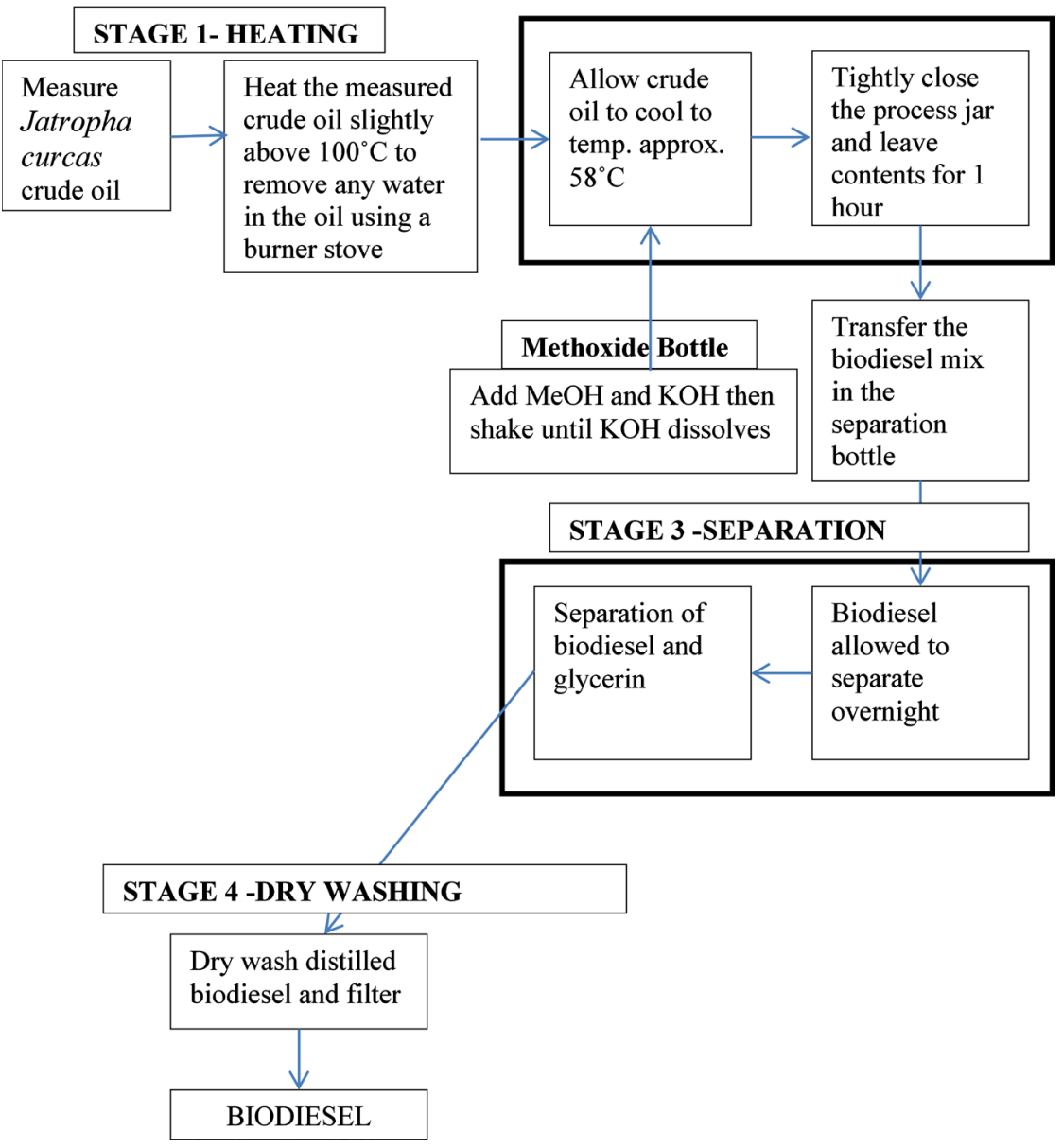

Figure 2. Schematic diagram of biodiesel production from Jatropha curcas crude oil. 
same procedure used for the standard and quantification was performed on major esters which was present on standard sample.

\subsubsection{Procedure}

Initially the standard was injected into the Gas Chromatograph-Mass Spectometry (GC-MS) then ran five (5) times with six (6) different concentrations of equal interval from $10 \mathrm{ppm}$ (part per million) to $1 \mathrm{ppm}$. At each concentration, peak areas and retention times were recorded and calibration curve was generated with each fatty acid in the standard sample which its calibration curve was used as reference for analysis of fatty acids in biodiesel samples. The same procedure was repeated for each biodiesel sample.

\subsubsection{Instrument Conditions}

The composition and quantity of fatty acid methyl ester (FAME) was determined according to test method ASTM D6584, using Agilent Technologies GC System 7890A gas chromatograph (GC) equipped with a HP-5MS capillary column $(30 \mathrm{~m} \times 250 \mu \mathrm{m} \times 0.25 \mu \mathrm{m})$ and an automated injector. The instrument which was used in the study was Agilent Technologies GC System 7890A gas chromatograph (GC) connected to the mass spectrometer with Triple-Axis detector. Helium was used as carrier gas at a pressure of $72 \mathrm{kPa}$ and flow rate of 64 $\mathrm{mL} / \mathrm{min}$ according to manufacturers' specification. $1 \mu \mathrm{L}$ of sample was injected using an automated injector. The initial oven temperature was set to $100^{\circ} \mathrm{C}$ for 4 minutes, which was then increased at a rate of $7^{\circ} \mathrm{C} / \mathrm{min}$ to $235^{\circ} \mathrm{C}$, then $10^{\circ} \mathrm{C} / \mathrm{min}$ to $300^{\circ} \mathrm{C}$ for 7 minutes. The injector and detector temperatures were set to $325^{\circ} \mathrm{C}$ allow these target molecules to volatize. Total run time was about $36 \mathrm{mi}-$ nutes.

\subsection{Fuel Quality Analysis}

Biodiesel produced from seeds collected from all the four regions of Botswana was investigated for the following fuel quality properties; kinematic viscosity analysis, density flash point, cloud point, pour point and energy content.

\section{1) Kinematic Viscosity Analysis}

Kinematic viscosity analysis was performed using a Fungilab Premium Series Viscometer (PREL 401024). The viscometer was coupled to a Thermo Fisher Scientific heating bath circulator. The temperature of the heating bath was then set to a maximum of $95^{\circ} \mathrm{C}$ as per the manufacturer specifications. On the viscometer, the low centipoise (LCP) spindle with its appropriate thermo station jacket was used since the samples analysed were of low viscosity.

The instrument was then started simultaneously with the heating bath set at $95^{\circ} \mathrm{C}$. The spindle speed was varied based on the torque values with the ideal range being $50 \%-95 \%$ as suggested by the manufacturer. Sample viscosity readings were performed at temperature intervals of $2^{\circ} \mathrm{C}$ from room temperature to $60^{\circ} \mathrm{C}$ because it was noticed that viscosity of biodiesel remains constant between $54^{\circ} \mathrm{C}$ to $60^{\circ} \mathrm{C}$. 


\section{2) Flashpoint Measurement}

Flashpoints of biodiesel fuel samples were determined using an automated Pensky-Martens Closed Cup Tester (Tanaka) according to the ASTM D93 test method. A $100 \mathrm{ml}$ brass test cup was filled with fuel sample to approximately 60 $\mathrm{ml}$ and covered with the test cover. The expected flash point, identification of fuel sample and procedure were then entered on the machine. The test mode used was the special mode (SPEC) since the samples tested were biodiesel fuels of unknown flash point. The test cup was heated and the sample agitated by a stirrer. At regular intervals, an ignition source was introduced into a test cup until a flash was detected. The procedure was repeated thrice for each sample and an average reading recorded.

\section{3) Cloud and Pour Point Analysis}

The cloud and pour points of the fuels were tested using the Normalab cloud and pour tester coupled with a cooling bath which uses methanol as the cooling medium. The temperature of the cooling bath was set to $-60^{\circ} \mathrm{C}$. The test sample was poured into a sample container up to a specified mark and then mounted on the motorised measurement head. The initial temperatures for cloud and pour point were entered prior to the test run. As soon as the specific temperature of cloud and pour point of the test sample were reached, the results were displayed on the screen and recorded.

\section{4) Energy Content}

The heating values of Jatropha curcas biodiesel fuels were determined using IKA C200 Calorimeter. The instrument was connected to a computer installed with CalWin calorimeter software for easy capture and display data. The experiment entails weighing the sample, oxygenating it and igniting it to determine its energy content. The decomposition vessel was charged with oxygen at a pressure of 30 bars for 30 seconds to ensure adequate oxygen for combustion process. The test run was initiated and the results were automatically saved in the computer. Total run time for each experiment was 9 minutes.

\section{Results and Discussions}

\subsection{Fatty Acid Composition}

Fatty acid composition of biodiesel is an important characteristic in biodiesel production. The properties of biodiesel fuel are determined by the quantity of each fatty acid present in the biodiesel fuel sample. Table 1 shows the results of fatty acid composition in biodiesel produced from Jatropha curcas oil from four different regions, namely, Paje, Serowe, Tsamaya and Mmadinare villages.

From the results in Table 1 it can be observed that the major fatty acids in Jatropha curcas biodiesel samples for all regions under review were the oleic, linoleic, palmitic and stearic with oleic being the dominant one. The reported percentage of oleic acid was $48.65 \%$ for Tsamaya followed by Paje at $43.14 \%$, Serowe at $41.90 \%$ and Mmadinare at $37.92 \%$. The results further demonstrate that the percentage composition of monounsaturated fatty acid found in different 
Table 1. Fatty Acid Composition of Biodiesel derived from Jatropha curcas oil from regions of Paje, Serowe, Tsamaya and Mmadinare.

\begin{tabular}{|c|c|c|c|c|c|c|}
\hline \multicolumn{2}{|r|}{ Fatty Acid } & \multirow{2}{*}{${ }^{\text {aS Structure }}$} & \multicolumn{4}{|c|}{ Relative Composition (\%) } \\
\hline & Scientific Name & & Paje & Serowe & Tsamaya & Mmadinare \\
\hline \multicolumn{7}{|l|}{ Saturated Acid } \\
\hline Palmitic & Hexadecanoic & $\mathrm{C} 16: 0$ & 14.22 & 15.12 & 18.06 & 15.03 \\
\hline Stearic & Octadecanoic & $\mathrm{C} 18: 0$ & 8.39 & 8.31 & 10.21 & 7.16 \\
\hline Total Saturatec & & & 22.61 & 23.42 & 28.27 & 22.19 \\
\hline \multicolumn{7}{|c|}{ Unsaturated Acid } \\
\hline Oleic & Cis-9-octadenoic & $\mathrm{C} 18: 1$ & 43.14 & 41.9 & 48.65 & 37.92 \\
\hline Linoleic & Cis-9,12-octadecadienoic & $\mathrm{C} 18: 2$ & 31.42 & 32.2 & 18.35 & 37.48 \\
\hline Palmitoleic & 9-hexadecenoic & $\mathrm{C} 16: 1$ & 1.01 & 1.09 & 1.23 & 1.03 \\
\hline Isooleic acid & 10-octadecenoic & C18:1 & 1.45 & 1.39 & 1.75 & 1.38 \\
\hline \multicolumn{3}{|c|}{ Total Unsaturated } & 77.02 & 76.58 & 69.98 & 77.81 \\
\hline \multicolumn{3}{|c|}{ Total monounsaturated } & 45.62 & 44.88 & 51.06 & 37.92 \\
\hline \multicolumn{3}{|c|}{ Total polyunsaturated } & 31.42 & 32.20 & 18.35 & 37.48 \\
\hline
\end{tabular}

${ }^{a}$ Number of carbon atoms: degree of unsaturation.

biodiesel samples is higher than that of polyunsaturated fatty acid. Several studies including [9] [10] [11] recommends that the best vegetable oil used for production of biodiesel should consist a larger amount of monounsaturated fatty acids compared to polyunsaturated fatty acids as oil containing relatively high amount of polyunsaturated fatty acids tends to exhibit a poor oxidation stability and it can compromise the fuel properties such as kinematic viscosity and impair fuel quality. In this case, the situation is favourable. Due to increased amount of unsaturated fatty acids in biodiesel fuel produced from oil seeds collected from Paje and Mmadinare regions, some of the fuel properties such as kinematic viscosity and cold properties are expected to be favourable.

Total saturated fatty acids (palmitic and stearic) of each biodiesel sample is $22.61 \%, 23.42 \%, 28.27 \%$ and $22.19 \%$ for Paje, Serowe, Tsamaya and Mmadinare respectively. Contrary to the discussions made earlier on poor oxidation stability of fuel with relatively high content of polyunsaturated fatty acids (linoleic), for a good oxidation stability, the fuel should have more of saturated fatty acid [8] [13]. Therefore, from the four biodiesel under review, biodiesel fuel from Tsamaya region would be expected to have a good oxidation stability due to relatively high percentage of saturated fatty acids of $28.27 \%$ and less polyunsaturated fatty acids of $18.35 \%$

\subsection{Physico-Chemical Fuel Properties}

\section{1) Kinematic Viscosity}

Kinematic viscosity is defined as a measure of the fluid's internal resistance to flow under gravitational forces. Figure 3 presents information obtained for ki- 
nematic viscosity of Jatropha curcas biodiesel fuels produced using seeds from different selected regions at different temperatures.

The results in Figure 3 show that all the fuels tested exhibit decrease in kinematic viscosity as the temperature increase. Azom [17] reported that the increase in temperature causes the kinetic energy to increase and the results in mobility of molecules hence reduction in kinematic viscosity. The observed profile in Figure 3 agrees with the one reported by Rashid and Anwar [18]. The ASTM D 6751 biodiesel standard prescribe an acceptable kinematic viscosity at $40^{\circ} \mathrm{C}$ for biodiesel to be at the range of 1.9 to $6.0 \mathrm{cSt}$. All the recorded results fall within the acceptable ASTM D 6751 biodiesel standard as demonstrated in Figure 4. These results guarantees a good combustion processes in the engine without leaving residual residues that can cause damage such as valve sticking and burning. The same observation was alluded by Anguebes-Franseschi et al. [19], who reported that higher viscosity tends to form larger droplets on injection resulting in poor combustion processes in compression ignition engines.

Most of the literatures reveal that kinematic viscosity can be affected by the degree of unsaturation [7] [8] [11] [20]. The authors alluded that decreasing degree of unsaturation leads to an increase in kinematic viscosity. In the current

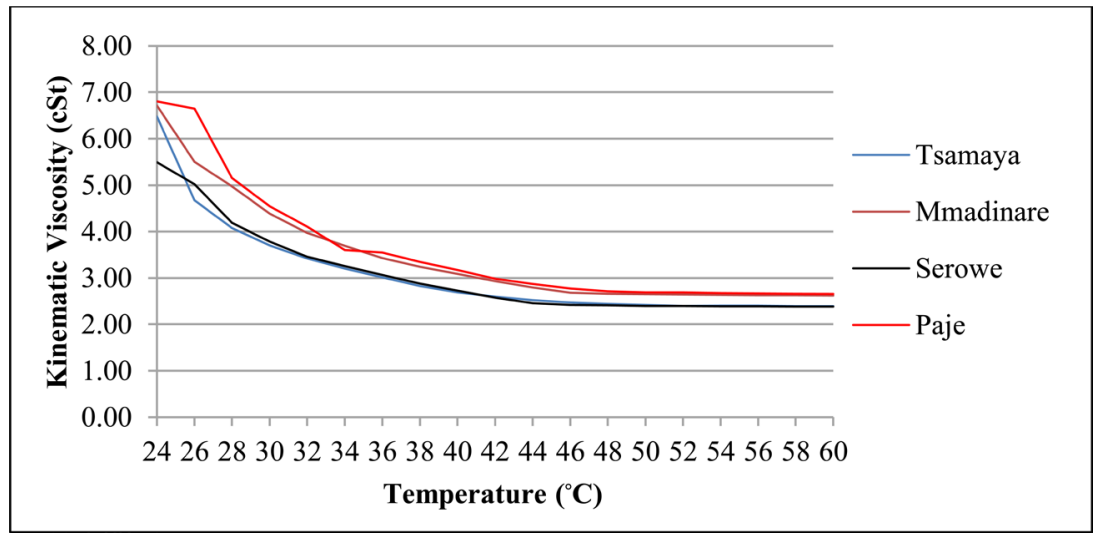

Figure 3. Kinematic Viscosity of Jatropha curcas biodiesel fuels at different temperatures.

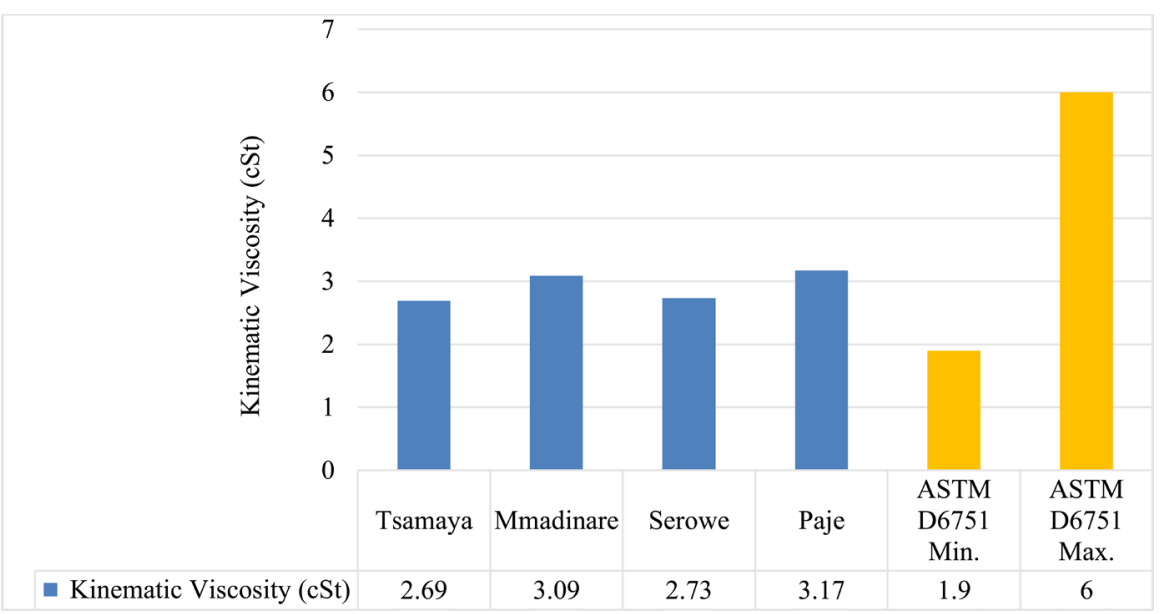

Figure 4. Kinematic viscosity of different Jatropha curcas biodiesel at $40^{\circ} \mathrm{C}$. 
study the results are opposite, an increase in degree of unsaturation leads to increase in kinematic viscosity. The situation could be due to reason given by Wardana et al. [21] who reported that the trend may be due to the molecular weight which is more influential on viscosity than the degree of unsaturation. In the present investigation, molecular weights of unsaturated fatty acids are more than that of saturated ones. For example, total unsaturated fatty acids for Paje and Mmadinare village were the highest at $77.81 \%$ and $77.02 \%$ respectively as demonstrated by Table 1 in Section 3.1. Corresponding kinematic viscosity of these study areas were also recorded at $3.17 \mathrm{cSt}$ and $3.09 \mathrm{cSt}$ for Paje and Mmadinare respectively, $13.9 \%$ and $15 \%$ higher than viscosity for Serowe and Tsamaya respectively.

\section{2) Density}

Density of the fuel is also an important fuel property that has an effect in the engine performance. It affects the pumping of the fuel because fuel injection pumps fuel by volume not by mass [8]. The authors stressed that the greater or lesser mass of fuel is injected in the compression ignition engine depend upon its density.

The results depicts in Figure 5 demonstrated that the biodiesel fuels produced from seeds collected from Paje and Mmadinare villages recorded high density of $0.9042 \mathrm{~g} / \mathrm{ml}$ and $0.9034 \mathrm{~g} / \mathrm{ml}$ respectively. Similarly, results for Serowe and Tsamaya villages recorded density of $0.8945 \mathrm{~g} / \mathrm{ml}$ and $0.8804 \mathrm{~g} / \mathrm{ml}$ respectively. The moderately higher densities recorded for biodiesel fuel of seeds from Mmadinare and Paje villages may be attributed to their higher degree of unsaturation fatty acids as shown in Table 1 in Section 3.1. Several authors including Hoekman et al. [8] and Refaat [22] reported that higher unsaturation leads to relatively high density of biodiesel fuels. Other biodiesel fuels densities reported are in the range of 0.85 to $0.95 \mathrm{~g} / \mathrm{ml} \mathrm{[23]} \mathrm{[24]} \mathrm{[25]} \mathrm{[26].} \mathrm{Additionally,} \mathrm{all} \mathrm{the} \mathrm{re-}$ ported densities for biodiesel fuels from all the four study areas under review are within the acceptable range of the EN 14214 biodiesel standard which stipulate density range of $0.86-0.90 \mathrm{~g} / \mathrm{ml}$. The ASTM D6751 biodiesel standard does not specify any range. The observation has also been stressed by several authors including Patel et al. [27].

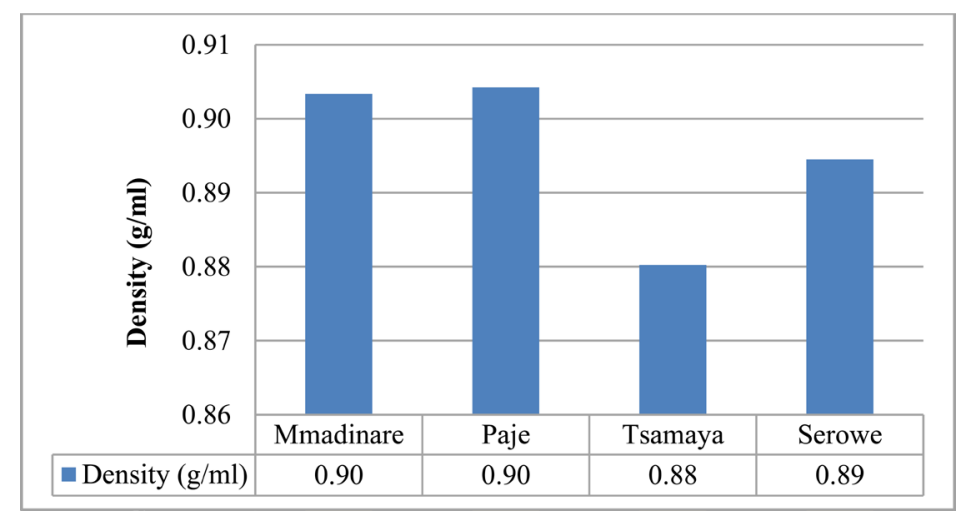

Figure 5. Density of Jatropha curcas biodiesel fuels from selected regions in Botswana. 


\section{3) Flash Point}

Flash point is fuel property that determines the safety of a fuel during its handling and storage. Figure 6 shows the results of flash points for Jatropha curcas biodiesel fuels produced using seeds from selected regions of Botswana.

The results show that biodiesel fuels produced from seeds collected from Mmadinare and Paje villages recorded relatively high flash point of about $177^{\circ} \mathrm{C}$ followed by Serowe with $157.17^{\circ} \mathrm{C}$ and Tsamaya with $146.50^{\circ} \mathrm{C}$. The results for Mmadinare and Paje biodiesel fuels are consistent with the results reported by [25] [28] [29] who reported flashpoint values in the range of $160^{\circ} \mathrm{C}-175^{\circ} \mathrm{C}$ for Jatropha curcas biodiesel. It is pertinent to mention that biodiesel standards such as EN14214 and ASTM D6751 put the minimum values for biodiesel flashpoint at $101^{\circ} \mathrm{C}$ and $93^{\circ} \mathrm{C}$ respectively. Results of this study therefore suggest that biodiesel produced using seeds collected from all regions under review satisfies both the two biodiesel standards.

Flashpoint of the biodiesel can be affected by its kinematic viscosity and density [30]. The authors alluded that high flashpoint of the fuel is influenced by higher kinematic viscosity and density of the fuel. Higher flashpoint values for biodiesel of seeds from Mmadinare and Paje villages may be influenced by relatively high kinematic viscosity and density of its biodiesel fuels as demonstrated by Figure 4 and Figure 5. Likewise, biodiesel fuels of seeds from Serowe and Tsamaya had lower flashpoint values possibly due to high content of saturated fatty acids as depicted in Table 1 in Section 3.1. Other studies have revealed that residual methanol from esterification process can have negative effects on the flashpoint temperature of biodiesel fuel [31]. These authors alluded that studies have shown that residual amount of methanol as low as $1 \%$ in the biodiesel fuel can lower its flashpoint from $170^{\circ} \mathrm{C}$ to less than $40^{\circ} \mathrm{C}$. In the current study, biodiesel samples from Jatropha curcas seeds from Serowe and Tsamaya areas may have recorded lower flashpoint temperatures possibly due to residual methanol from the esterification process.

The results also demonstrated the interdependence of the flash point property of biodiesel fuel with other biodiesel properties such as kinematic viscosity and

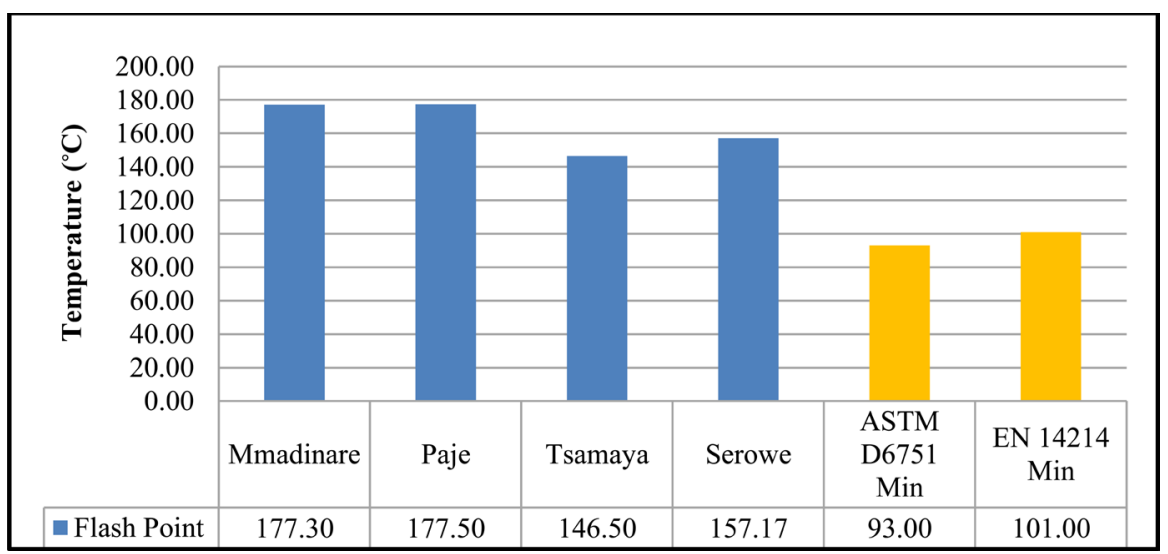

Figure 6. Flashpoints of Jatropha curcas biodiesel fuels from selected region in Botswana. 
density. The investigation demonstrated that the higher the kinematic viscosity and density of the biodiesel fuel the higher the flash point. Furthermore, the investigation also demonstrated that high content of saturated fatty acids results in low value of flash point of the biodiesel fuel.

\section{4) Cold Flow Properties}

The low temperature properties which were investigated in the present study were Pour Point (PP) and Cloud Point (CP). The results for the two properties are presented in Figure 7 and Figure 8.

Cloud point is defined as the highest temperature at which crystal growth of the biodiesel fuel is large enough (diameter $\geq 0.5 \mu \mathrm{m}$ ) to be noticed while pour point is the lowest temperature at which the fluid will pour [32]. The two properties are important parameters to observe how the biodiesel fuel will perform under low temperature conditions. Hoekman et al. [23] and Wardana et al. [33] reported that both the cloud point and pour point of biodiesel fuels are mainly influenced by the presence of saturated fatty acids in biodiesel fuels. Extended exposure of the biodiesel fuel to temperatures at or lower than cloud point or pour point temperatures results in crystallation or biodiesel fluid starting to pour. Kumar et al. [34] reported that crystals in the fuel make it difficult for fuel to flow in engine, ultimately resulting in choking of engine and incomplete combustion.

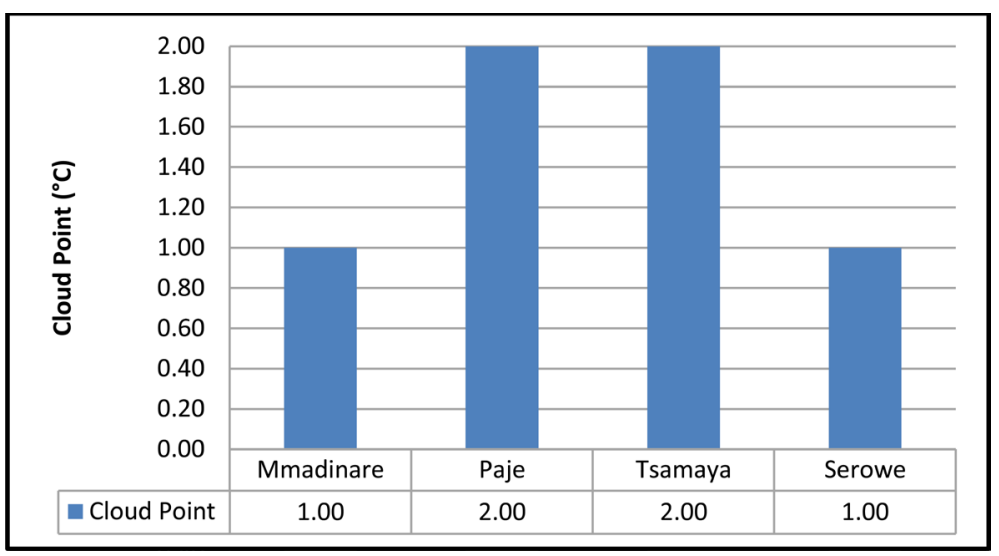

Figure 7. Cloud point of Jatropha curcas biodiesel fuels from selected region in Botswana.

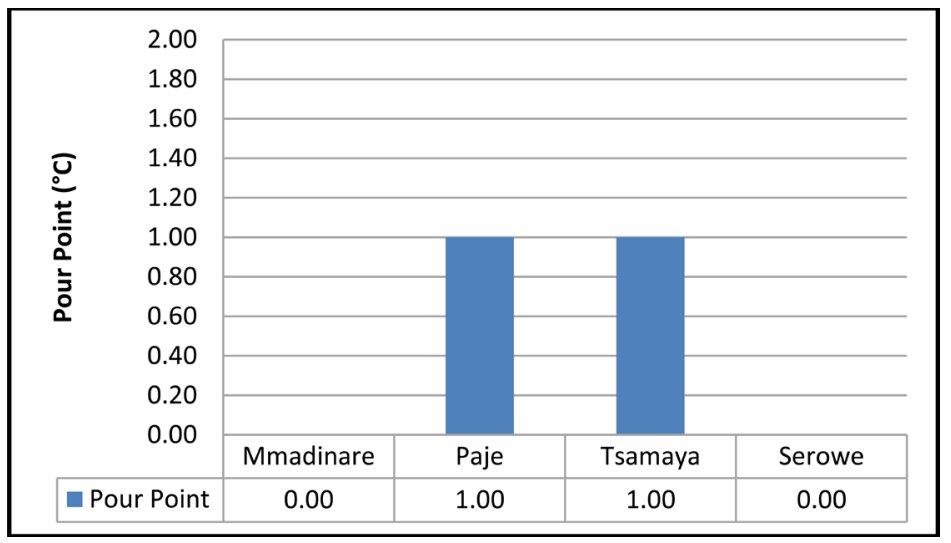

Figure 8. Pour point of Jatropha curcas biodiesel fuels from selected regions in Botswana. 
The results as depicted in Figure 7, shows that biodiesel fuel of seeds from Tsamaya and Paje areas recorded equal values of cloud point of $2^{\circ} \mathrm{C}$ followed by biodiesel fuel of seeds from Mmadinare and Serowe regions at $1^{\circ} \mathrm{C}$. Variation in the results may be attributed to the presence of saturated fatty acids present in the biodiesel [8]. The authors reported that feedstocks with highly saturated fatty acids produce biodiesel fuels with poor cold flow properties. Generally, biodiesel fuels with high concentration of saturated fatty acids tend to have high cloud point temperature. From the results in Table 1 in Section 3.1, biodiesel fuel from seeds for Tsamaya region recorded relatively high-saturated fatty acids, thus $20 \%$ and $17.16 \%$ higher compared to saturated fatty acids recorded for Paje and Serowe regions. All these may justify why there is slight difference of cloud point for biodiesel fuels from Tsamaya and Paje regions. Other researches such as [1] [35] [33] reported cloud points in the range of $2^{\circ} \mathrm{C}$ to $5^{\circ} \mathrm{C}$ for Jatropha curcas biodiesel fuel.

Pour point is another important parameter similar to cloud point as it also focuses on cold properties of fuel. The results in Figure 8 shows that the biodiesel fuels from Tsamaya and Paje regions recorded the highest pour point temperatures of $1^{\circ} \mathrm{C}$. Biodiesel fuels from Mmadinare and Serowe regions recorded the pour points temperatures of $0^{\circ} \mathrm{C}$. Like for cloud point, the slight difference in the results may be attributed to the presence of saturated fatty acids present in the biodiesel [8]. From the fatty acid composition Table 1 in Section 3.1, the results shows that biodiesel fuels from Tsamaya and Paje regions recorded high degree of saturated fatty acids which may be the main reason for high pour point temperatures.

Other authors have reported pour point values in the range of $-5^{\circ} \mathrm{C}$ to $5^{\circ} \mathrm{C}$ for different biodiesel feedstock including Jatropha curcas [36] [37] [38] [39]. The pour point results obtained in the current study are consistence with pour point values in other studies.

\section{5) Energy Content}

The study also investigated the energy content of the biodiesel fuel from Jatropha curcas seeds obtained from selected regions of Botswana and the results are depicted in Figure 9.

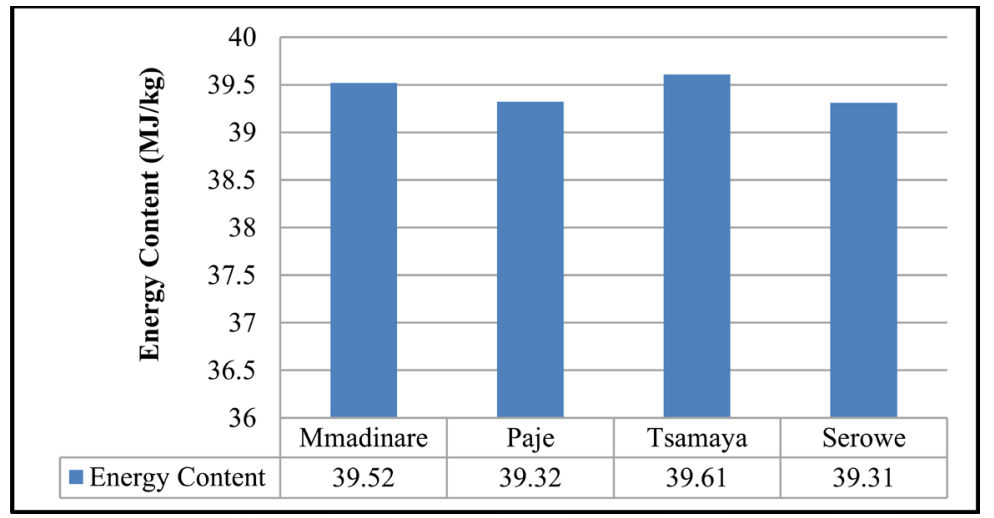

Figure 9. Energy content of Jatropha curcas biodiesel fuels from selected regions in Botswana. 
All the energy content values of the biodiesel fuels are in the average of 39.00 $\mathrm{MJ} / \mathrm{kg}$, biodiesel fuel produced from Jatropha curcas seeds collected from Tsamaya had energy content of $39.61 \mathrm{MJ} / \mathrm{kg}$ followed by biodiesel fuel from Mmadinare at $39.52 \mathrm{MJ} / \mathrm{kg}$. Paje and Serowe had the least at $39.32 \mathrm{MJ} / \mathrm{kg}$ and $39.31 \mathrm{MJ} / \mathrm{kg}$ respectively. The minimum and maximum percentage variation observed was $0.23 \%$ and $0.76 \%$ respectively which is quite insignificant. Therefore, this means that all the biodiesel fuels under review will probably have the same behaviour when it comes to certain engine performance parameter such as specific fuel consumption which are influenced by energy content of fuel. The obtained results fall within the same range of results reported in other studies such as [35] [40] [41] [42]. The authors reported energy content values in the range between 37 - $40 \mathrm{MJ} / \mathrm{kg}$.

\section{Conclusions}

The main purpose of the present study was to investigate effects of fatty acids composition on fuel properties of Jatropha curcas biodiesel fuel. Relevant experiments were successfully carried out and the following conclusions were arrived at:

1) The physicochemical fuel properties of biodiesel investigated are influenced by the fatty acid composition. The experimentally determined kinematic viscosity, density and flashpoint values are influenced by the degree of unsaturation of the fatty acid mixture. Biodiesel of Jatropha curcas seeds obtained from Paje and Mmadinare regions had higher values of kinematic viscosity, density and flashpoint than other regions due to high proportions of unsaturated fatty acids.

2) Biodiesel of Jatropha curcas seeds obtained from Tsamaya and Paje regions had slightly higher cloud and pour point due to dominant presence of saturated fatty acids.

3) Energy content of all the biodiesel was averagely the same and this signifies that the energy content of the biodiesel investigated is independent of fatty acid composition.

4) Although some differences in values of physicochemical properties were observed in all the parameters investigated, all the biodiesel fuels were within the European (EN14214) and American (ASTM D6751) biodiesel standards in terms of kinematic viscosity, density and flashpoint. As for cold flow properties and energy content, the results were comparable to other studies.

It is therefore appropriate to conclude that fatty acids composition has great influence on fuel properties of Jatropha curcas biodiesel.

\section{Acknowledgements}

The authors gratefully acknowledge the Department of Energy, Botswana, for providing financial support to carry out the work.

\section{Conflicts of Interest}

The authors declare no conflicts of interest regarding the publication of this paper. 


\section{References}

[1] Koh, M.Y. and Ghazi, T.I.M. (2011) A Review of Biodiesel Production from Jatropha curcas L. Oil. Renewable and Sustainable Energy Reviews, 15, 2240-2251. https://doi.org/10.1016/j.rser.2011.02.013

[2] Takase, M. (2015) An Expatiate Review of Neem, Jatropha, Rubber and Karanja as Multipurpose Non-Edible Biodiesel Resources and Comparison of Their Fuel, Engine and Emission Properties. Renewable and Sustainable Energy Reviews, 43, 495-520. https://doi.org/10.1016/j.rser.2014.11.049

[3] Demirbas, A. (2009) Potential Resources of Non-edible Oils for Biodiesel. Energy Sources, Part B: Economics, Planning, and Policy, 4, 310-314. https://doi.org/10.1080/15567240701621166

[4] Yang, L., Takase, M., Zhang, M., Zhao, T. and Wu, X. (2014) Potential Non-Edible Oil Feedstock for Biodiesel Production in Africa: A Survey. Renewable and Sustainable Energy Reviews, 38, 461-477. https://doi.org/10.1016/j.rser.2014.06.002

[5] Rutz, D. and Rainer, J. (2007) Technology Handbook.

[6] Sokoto, M., Hassan, L., Dangoggo, S., Ahmad, H. and Uba, A. (2011) Influence of Fatty Acid Methyl Esters on Fuel properties of Biodiesel Produced from the Seeds Oil of Curcubita pepo. Nigerian Journal of Basic and Applied Sciences, 19, 81-86. https://doi.org/10.4314/njbas.v19i1.69348

[7] Knothe, G. (2005) Dependence of Biodiesel Fuel Properties on the Structure of Fatty Acid Alkyl Esters. Fuel Processing Technology, 86, 1059-1070. https://doi.org/10.1016/j.fuproc.2004.11.002

[8] Hoekman, S.K., Broch, A., Robbins, C., Ceniceros, E. and Natarajan, M. (2012) Review of Biodiesel Composition, Properties, and Specifications. Renewable and Sustainable Energy Reviews, 16, 143-169. https://doi.org/10.1016/j.rser.2011.07.143

[9] Akbar, E., Yaakob, Z., Kamarudin, S.K., Ismail, M. and Salimon, J. (2009) Characteristic and Composition of Jatropha curcas Oil Seed from Malaysia and Its Potential as Biodiesel Feedstock Feedstock. European Journal of Scientific Research, 29, 396-403.

[10] Emil, A., Yaakob, Z., Kumar, M.N.S., Jahim, J.M. and Salimon, J. (2010) Comparative Evaluation of Physicochemical Properties of Jatropha Seed Oil from Malaysia, Indonesia and Thailand. Journal of the American Oil Chemists' Society, 87, 689-695. https://doi.org/10.1007/s11746-009-1537-6

[11] Saravanan, S. and Nagarajan, G. (2011) Effects of Single Double Bond in the Fatty Acid Profile of Biodiesel on Its Properties as a CI Engine Fuel. International Journal of Energy and Environment, 2, 1141-1146.

[12] Kinast, J.A. (2003) Production of Biodiesels from Multiple Feedstocks and Properties of Biodiesels and Biodiesel/Diesel Blends. National Renewable Energy Lab., Golden, CO, p. 57. https://doi.org/10.2172/15003582

[13] Sharma, Y.C. and Singh, B. (2009) Development of Biodiesel: Current Scenario. Renewable and Sustainable Energy Reviews, 13, 1646-1651. https://doi.org/10.1016/j.rser.2008.08.009

[14] Botswana Government Report (2007) The Feasibility Study of Production and Use of Biofuels in Botswana. Department of Energy.

[15] Karaj, S. and Müller, J. (2009) Optimization of Mechanical Extraction of Jatropha curcas Seeds. Landtechnik, 64, 164-167.

[16] Achten, W. (2010) Sustainability Evaluation of Biodiesel from Jatropha curcas L. A Life Cycle Oriented Study. Ph.D. Dissertation, Arenberg Doctoral School, KU Leuren. 
http://citeseerx.ist.psu.edu/viewdoc/download?doi=10.1.1.695.43\&rep=rep1\&type= $\underline{\mathrm{pdf}}$

[17] Azom (2013) How Does Temperature Change Viscosity in Liquids and Gases? AZo Materiales. http://www.azom.com/article.aspx?ArticleID=10036

[18] Rashid, U. and Anwar, F. (2008) Production of Biodiesel through Optimized Alkaline-Catalyzed Transesterification of Rapeseed Oil. Fuel, 87, 265-273. https://doi.org/10.1016/j.fuel.2007.05.003

[19] Anguebes-Franseschi, F., et al. (2019) Physical and Chemical Properties of Biodiesel Obtained from Amazon Sailfin Catfish (Pterygoplichthys pardalis) Biomass Oil. Journal of Chemistry, 2019, Article ID: 7829630. https://doi.org/10.1155/2019/7829630

[20] Demirbas, A. (2008) Relationships Derived from Physical Properties of Vegetable Oil and Biodiesel Fuels. Fuel, 87, 1743-1748. https://doi.org/10.1016/j.fuel.2007.08.007

[21] Wardana, I.N.G., Widodo, A. and Wijayanti, W. (2018) Improving Vegetable Oil Properties by Transforming Fatty Acid Chain Length in Jatropha Oil and Coconut.

[22] Refaat, A.A. (2009) Correlation between the Chemical Structure of Biodiesel and Its Physical Properties. International Journal of Environmental Science \& Technology, 6, 677-694. https://doi.org/10.1007/BF03326109

[23] Demirbas, A. (2008) Biodiesel: A Realistic Fuel Alternative for Diesel Engine. Springer.

[24] Murugesan, A., Umarani, C., Subramanian, R. and Nedunchezhian, N. (2009) Bio-Diesel as an Alternative Fuel for Diesel Engines-A Review. Renewable and Sustainable Energy Reviews, 13, 653-662. https://doi.org/10.1016/j.rser.2007.10.007

[25] Ong, H.C., Masjuki, H.H., Mahlia, T.M.I., Silitonga, A.S., Chong, W.T. and Yusaf, T. (2014) Engine Performance and Emissions Using Jatropha curcas, Ceiba pentandra and Calophyllum inophyllum Biodiesel in a CI Diesel Engine. Energy, 69, 427-445. https://doi.org/10.1016/j.energy.2014.03.035

[26] Meher, L.C., Vidya Sagar, D. and Naik, S.N. (2004) Technical Aspects of Biodiesel Production by Transesterification-A Review. Renewable and Sustainable Energy Reviews, 10, 248-268. https://doi.org/10.1016/j.rser.2004.09.002

[27] Patel, A., Arora, N., Mehtani, J., Pruthi, V. and Pruthi, P.A. (2017) Assessment of Fuel Properties on the Basis of Fatty Acid Profiles of Oleaginous Yeast for Potential Biodiesel Production. Renewable and Sustainable Energy Reviews, 77, 604-616. https://doi.org/10.1016/j.rser.2017.04.016

[28] Mangaraj, S., Singh, R. and Pajnoo, R.K. (2013) Post Production System of Jatropha for Use as Biodiesel. vol. 1, no. 1, 85-97.

[29] Narayana Reddy, J. and Ramesh, A. (2006) Parametric Studies for Improving the Performance of a Jatropha Oil-Fuelled Compression Ignition Engine. Renewable Energy, 31, 1994-2016. https://doi.org/10.1016/j.renene.2005.10.006

[30] Narayana, R., Ramadhas, A.S., Nallusamy, N. and Sakthivel, P. (2010) Relationships among the Physical Properties of Biodiesel and Engine Fuel System Design Requirement. International Journal of Energy and Environment, 1, 919-926.

[31] Van Gerpen, J., Shanks, B., Pruszko, R. and Clements, D. (2004) Biodiesel Production Technology Biodiesel Production Technology. Contract, 87, 3170-3175.

[32] Moser, B.R. (2009) Biodiesel Production, Properties, and Feedstocks. In Vitro Cellular \& Developmental Biology-Plant, 45, 229-266.

https://doi.org/10.1007/s11627-009-9204-Z 
[33] Folaranmi, J. (2013) Production of Biodiesel (B100) from Jatropha Oil Using Sodium Hydroxide as Catalyst. Journal of Petroleum Engineering, 2013, Article ID: 956479. https://doi.org/10.1155/2013/956479

[34] Kumar, P., Sharma, M.P. and Dwivedi, G. (2016) Impact of Ternary Blends of Biodiesel on Diesel Engine Performance. Egyptian Journal of Petroleum, 25, 255-261. https://doi.org/10.1016/j.ejpe.2015.06.010

[35] Lu, H., Liu, Y., Zhou, H., Yang, Y., Chen, M. and Liang, B. (2009) Production of Biodiesel from Jatropha curcas L. Oil. Computers \& Chemical Engineering, 33, 1091-1096.

http://www.scopus.com/inward/record.url?eid=2-s2.0-63749123208\&partnerID=40 \&md5=3f6f523b1980132ed2280cb7e8b2e556 https://doi.org/10.1016/j.compchemeng.2008.09.012

[36] Achten, W.M., Mathijs, E., Verchot, L., Singh, V.P., Aerts, R. and Muys, B. (2007) Jatropha Biodiesel Fueling Sustainability? Biofuels, Bioproducts and Biorefining, 1, 283-291. https://doi.org/10.1002/bbb.39

[37] Tyson, S. (2006) Biodiesel: Handling and Use Guidelines. US, Dept of Energy.

[38] Edith, O. (2012) Factors Affecting the Cold Flow Behaviour of Biodiesel and Methods for Improvement-A Review. Pertanika Journal of Science and Technology, 20, 1-14.

[39] Boonmee, K., Chuntranuluck, S., Punsuvon, V. and Silayoi, P. (2010) Optimization of Biodiesel Production from Jatropha Oil (Jatropha curcas L.) Using Response Surface Methodology. Kasetsart Journal-Natural Science, 44, 290-299.

[40] Pramanik, K. (2003) Properties and Use of Jatropha curcas Oil and Diesel Fuel Blends in Compression Ignition Engine. Renewable Energy, 28, 239-248. https://doi.org/10.1016/S0960-1481(02)00027-7

[41] Patil, P.D. and Deng, S. (2009) Optimization of Biodiesel Production from Edible and Non-Edible Vegetable Oils. Fuel, 88, 1302-1306.

https://doi.org/10.1016/j.fuel.2009.01.016

[42] Oliveira, L.E. and Da Silva, M.L.C.P. (2013) Comparative Study of Calorific Value of Rapeseed, Soybean, Jatropha curcas and Crambe Biodiesel. International Conference on Renewable Energies and Power Quality, 1, 679-682.

https://doi.org/10.24084/repqj11.411 